\title{
Prognostic significance of L1 cell adhesion molecule in cancer patients: A systematic review and meta-analysis
}

\author{
Teng Hua ${ }^{1, *}$, Shuangge Liu ${ }^{1, *}$, Xiaoyan Xin ${ }^{1, *}$, Zhishan Jin ${ }^{1}$, Qibin Liu ${ }^{2}$, Shuqi Chi ${ }^{1}$, \\ Xiaoxiao Wang ${ }^{1}$, Hongbo Wang ${ }^{1}$ \\ ${ }^{1}$ Department of Gynaecology and Obstetrics, Union Hospital, Tongji Medical College, Huazhong University of Science and \\ Technology, Wuhan 430022, PR China \\ ${ }^{2}$ Department of Surgery, Wuhan Pulmonary Hospital, Wuhan 430000, PR China \\ *These authors have contributed equally to this work \\ Correspondence to: Hongbo Wang, email: hb_wang1969@sina.com
}

Keywords: cancer, L1 cell adhesion molecule, prognosis, meta-analysis

Received: August 29, 2016

Accepted: October 24, 2016

Published: November 09, 2016

\section{ABSTRACT}

The L1 cell adhesion molecule (L1CAM) extensively participates in nervous system development and the malignant progression of human tumours. The prognostic value of L1CAM for the survival of patients with solid tumours remains controversial. The present meta-analysis was thus performed to highlight the relationship between L1CAM expression and prognosis in cancer patients. Relevant publications were identified after searching several widely used databases, including PubMed, EMBASE and the ISI Web of Science. A fixed-effect or random-effect meta-analytical model was employed to correlate L1CAM expression with different outcome measures in both entire tumours and stratified subgroups. 37 studies in total with 8552 patients were eligible for the final analysis. Combined hazard ratios (HRs) and $95 \%$ confidence intervals (CIs) suggested that high L1CAM expression had an unfavourable impact on overall survival ( $\mathrm{HR}=2.06,95 \% \mathrm{CI} 1.65-2.57, \mathrm{P}<0.001)$, disease-specific survival ( HR=2.45, 95\%CI 1.48-4.05, $P<0.001)$, disease-free survival ( $H R=2.42,95 \% C I 1.4-$ 4.19, $P=0.002)$ and progression-free survival/recurrence-free survival $(H R=2.07$, $95 \% \mathrm{CI} 1.41-3.05, \mathrm{P}<0.001)$. Subgroup analysis revealed a similar correlation in most tumour types. Overall, L1CAM might be an effective poor prognostic factor for patients with various tumour types.

\section{INTRODUCTION}

Normally expressed in neural systems, L1 cell adhesion molecule (L1CAM) performs an essential role in nervous neural cell adhesion and migration, such as neurite outgrowth guidance, axon bundling, myelination, synaptogenesis and long-term potentiation [1]. Over the past decade, the knowledge of L1CAM in the cancer field has developed rapidly. The aberrant expression of L1CAM protein is closely correlated with the aggressive behaviour of several human malignancies. Mechanistic studies have indicated that forced changes in L1CAM expression distinctly alter cellular properties, including invasion, migration, proliferation and chemoresistance [2-4].

Although a majority of studies have shown that high L1CAM expression is interrelated with poor prognosis, the association between L1CAM overexpression and the outcome of cancer patients remains unknown. The overexpression of L1CAM in ovarian and endometrial cancer has a critical value in patient outcome prediction [5]. In addition, high L1CAM expression was associated with the progression of many other human cancers, including triple negative breast cancer [6], non-small lung cancer [7], pancreatic ductal adenocarcinoma [8], renal cell carcinoma [9], melanoma [10] and glioblastoma [11]. Conversely, Wachowiak and colleagues reported that the expression of L1CAM exhibited a favourable prognostic effect in children with neuroblastoma [12].

Although numerous studies have focused on the prognostic role of L1CAM expression in human solid tumours, most of these studies included only a limited number of patients, and the results of each individual study were not conclusive. We therefore performed a comprehensive meta-analysis to elucidate the prognostic 
value of L1CAM expression in all solid tumours using a relatively large sample size from 37 studies covering 8552 patients.

\section{RESULTS}

\section{Study selection and characteristics}

The detailed study selection is shown as Figure 1. A total of 1506 records were identified. Thirty-seven eligible studies [5-9, 12-43] encompassing 8552 patients were included in this meta-analysis. All studies were published between 2005 and 2016, and approximately $67.57 \%$ of them were published after 2010. The participants in the studies covered a wide variety of countries and cancer types. Most of the studies were from European (40.54\%) and Asian (35.14\%) countries, and the majority of the studies reported endometrial cancer $(24.3 \%)$, followed by ovarian $(10.8 \%)$ and colorectal cancer $(10.8 \%)$; bile duct, hepatic, gallbladder, brain, lung, and vulvar cancers were only described once each. Immunohistochemical (IHC) staining was the predominant detection method for L1CAM, supplemented with RTPCR and ELISA. For IHC, UJ127.11 and L1-14.10 were the most commonly used specific antibodies for L1CAM. In addition, $>5 \%$ and $>10 \%$ positive tumour cells and scores $\geq 1$ were all proper cut-off values for OS, and $>10 \%$ positive tumour cells was a proper cutoff value for DFS, while no proper cut-off value was determined for PFS/RFS (Supplementary Table S1). The main characteristics of the 37 eligible studies are shown in Table 1. More specifically, most of the studies (27/37) described a positive relationship between high L1CAM expression and clinicopathological features, including advanced clinical stages, aggressive histologic grade, lymph node involvement and distant metastasis (data not shown). Additionally, $91.89 \%$ of the NOS scores for the included studies were $\geq 7$, indicating a high quality for most of the studies. The detailed characteristics are listed in Supplementary Table S2.

Cancer patients with excessive L1CAM expression had a poor prognosis. The association was significant and strong for all endpoints. The inverse correlation between L1CAM expression and outcome was dominant for DSS

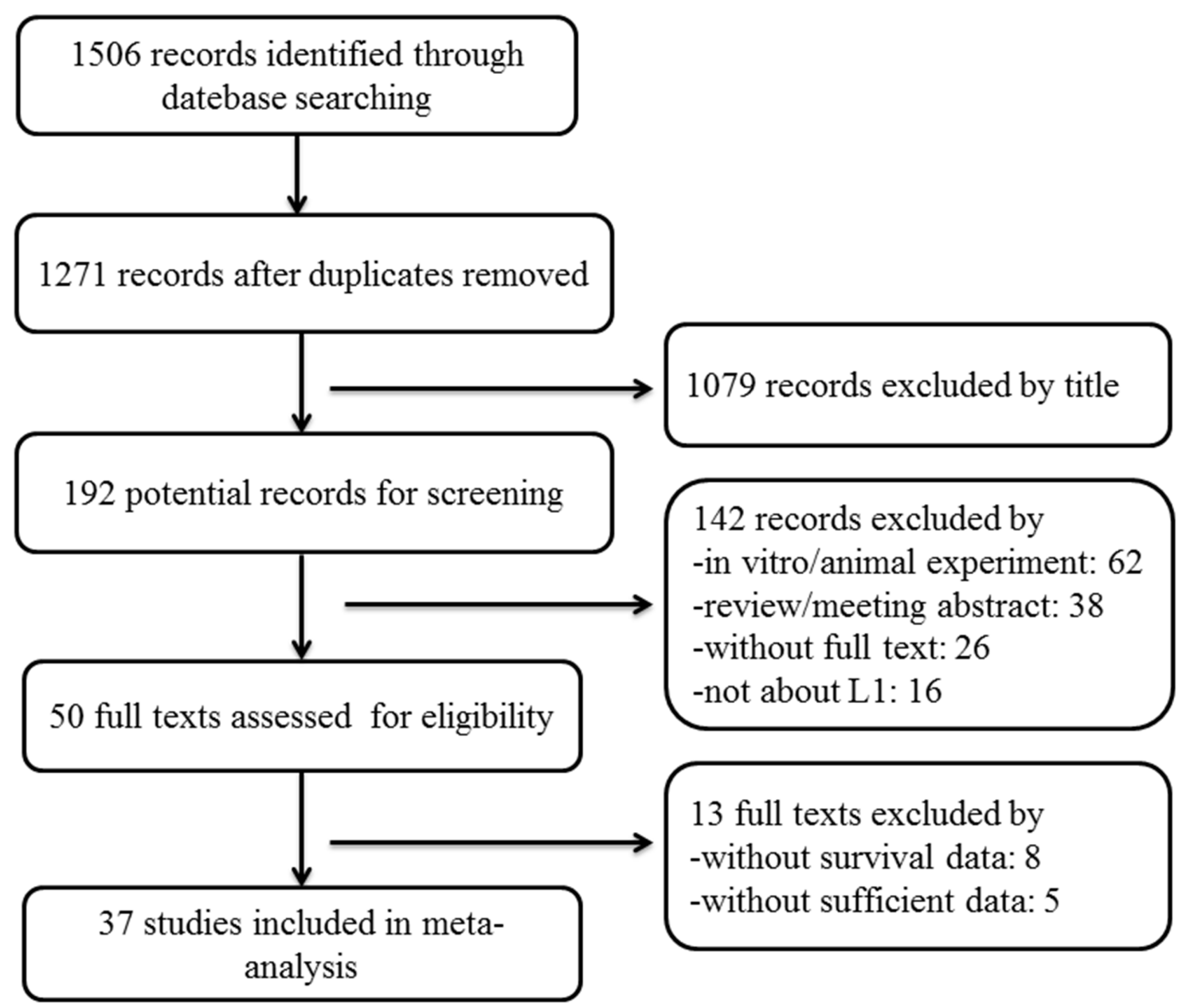

Figure 1: Flow chart of the literature search and selection. 
Table 1: Main characteristics of studies exploring the relationship between L1CAM expression and tumor prognosis

\begin{tabular}{|c|c|c|c|c|c|c|c|c|c|c|}
\hline Author & Year & Country & Cancer type & $\begin{array}{l}\text { Stage/ } \\
\text { grade }\end{array}$ & $\begin{array}{c}\text { No. of } \\
\text { patients }\end{array}$ & $\begin{array}{c}\text { Age } \\
\text { Median(range) }\end{array}$ & $\begin{array}{l}\text { Follow-up time } \\
\text { Median(range) }\end{array}$ & $\begin{array}{l}\text { Detection } \\
\text { method }\end{array}$ & Cut-off & Outcomes \\
\hline Allory & 2005 & France & Renal cell cancer & pT1-pT4 & 103 & NA & $34.7 \mathrm{~m}(2-133)$ & $\mathrm{IHC}(\mathrm{mAb} 272)$ & $>10 \%$ & DFS \\
\hline Kaifi & 2006 & Germany & GIST & NA & 55 & $56.35 \mathrm{y}$ & $41 \mathrm{~m}$ & IHC(UJ127) & $\geq 10 \%$ & RFS \\
\hline Boo & 2007 & Korea & Colorectal cancer & I-IV & 138 & $57.9 \mathrm{y}(18-82)$ & $70.9 \mathrm{~m}(3-129)$ & IHC(UJ127) & $>5 \%$ & OS \\
\hline Kaifi & 2007 & Germany & Colorectal cancer & pT1-pT4 & 247 & $65 \mathrm{y}$ & $46 \mathrm{~m}$ & IHC(UJ127) & score $>1$ & DSS, OS \\
\hline Wachowiak & 2007 & Germany & Neuroblastoma & Grade 1-3 & 66 & $30 \mathrm{~m}$ & $72 \mathrm{~m}$ & IHC(UJ127) & NA & DFS, OS \\
\hline Daponte & 2008 & Greece & Ovarian cancer & Grade 1-3 & 95 & NA & $3 y$ & IHC(UJ127) & score $>1$ & PFS \\
\hline Zecchini & 2008 & Italy & Ovarian cancer & I-IV & 211 & NA & 3.9 y(0.14-11.47) & IHC(NA) & Membrane $(+)$ & DFS, OS \\
\hline KATO & 2009 & Japan & Colorectal cancer & I-IV & 71 & NA & $34 \mathrm{~m}(1-67)$ & IHC(UJ127) & score $>2$ & OS \\
\hline Kim & 2009 & Korea & $\begin{array}{l}\text { Neuroendocrine } \\
\text { tumor }\end{array}$ & I-IIIB & 55 & $64 \mathrm{y}(24-80)$ & $52 \mathrm{~m}(2.6-133.7)$ & IHC(A10-A3) & $>5 \%$ & DFS, OS \\
\hline Kodera & 2009 & Japan & Gastric cancer & pT3 & 72 & $59.5 \mathrm{y}$ & $6.11 \mathrm{y}(5-9.01)$ & IHC(UJ127) & $\geq 10 \%$ & OS \\
\hline Schroder & 2009 & Germany & Breast cancer & pT1-pT4 & 167 & $55.5 \mathrm{y}(29-85)$ & 84 m(8-169) & $\begin{array}{l}\text { DNA- } \\
\text { microarray }\end{array}$ & $\geq 200$ & DFS, OS \\
\hline $\mathrm{Li}$ & 2009 & Korea & cholangiocarcinoma & I-IV & 75 & $65 \mathrm{y}(48-84)$ & $16 \mathrm{~m}(1-94)$ & IHC(A10-A3) & scores $=+2 /+3$ & PFS, OS \\
\hline Ben & 2010 & China & PDAC & pT1-pT3 & 94 & 59 y $(31-79)$ & $20 \mathrm{~m}(3-45)$ & IHC(UJ127) & score $\geq 30$ & OS \\
\hline BERGMANN & 2010 & Germany & PDAC & pT3-pT4 & 110 & $63.2 \mathrm{y}(37-88)$ & $20 \mathrm{~m}(2-64)$ & $\mathrm{IHC}(14.10)$ & $\geq 20 \%$ & OS \\
\hline FANG & 2010 & China & Colorectal Cancer & Dukes A-D & 142 & $55 \mathrm{y}(15-78)$ & $>5 \mathrm{y}$ & IHC(UJ127) & $>30 \%$ & OS \\
\hline Huszar & 2010 & Germany & Endometrial cancer & IA-IIB & 272 & $\begin{array}{c}66.6 \text { y }(32.7- \\
87.7)\end{array}$ & NA & $\mathrm{IHC}(14.10)$ & scores $\geq 1$ & RFS \\
\hline Tsutsumi & 2011 & Japan & PDAC & Grade 1-3 & 107 & $66 \mathrm{y}(37-80)$ & $15.8 \mathrm{~m}$ & IHC(UJ127) & $\geq 10 \%$ & OS \\
\hline Choi & 2011 & Korea & Gallbladder cancer & I-IV & 69 & $67 \mathrm{y}(35-87)$ & $37 \mathrm{~m}(1-117)$ & IHC(A10-A3) & $>5 \%$ & DFS, OS \\
\hline Doberstein & 2011 & Germany & Renal cell cancer & pT1-pT3 & 282 & 63 y(29-88) & $40 \mathrm{~m}(1-140)$ & $\operatorname{IHC}(14.10)$ & $\geq 5 \%$ & OS \\
\hline Tischler & 2011 & Switzerland & $\begin{array}{l}\text { Non-small cell lung } \\
\text { cancer }\end{array}$ & pT1-pT4 & 472 & NA & $\begin{array}{c}25 \mathrm{~m}(0-169 \\
\text { PFS }) ; 51 \mathrm{~m}(1- \\
169, \mathrm{OS})\end{array}$ & $\mathrm{IHC}(14.10)$ & scores $\geq 1$ & PFS, OS \\
\hline Zander & 2011 & Germany & GIST & NA & 65 & $61 \mathrm{y}(28-81)$ & $37 \mathrm{~m}(0-273)$ & ELISA & $>2 \mathrm{ng} / \mathrm{ml}$ & RFS \\
\hline Bondong & 2012 & Germany & Ovarian cancer & IIA-IV & 232 & $57 \mathrm{y}(18-85)$ & $31 \mathrm{~m}$ & ELISA & $5.4 \mathrm{ng} / \mathrm{ul}$ & PFS, OS \\
\hline Guo & 2012 & China & $\begin{array}{l}\text { Hepatocellular } \\
\text { cancer }\end{array}$ & I-IV & 130 & NA & $8.6 \mathrm{y}$ & IHC(UJ127) & scores $\geq 4$ & DFS, OS \\
\hline Chen & 2013 & China & Gastric cancer & I-IV & 156 & NA & $30 \mathrm{~m}(3-112)$ & $\mathrm{IHC}(5 \mathrm{G} 3)$ & scores $\geq 1$ & OS \\
\hline ZHANG & 2013 & China & Breast cancer & Grade 1-3 & 97 & 53 y (28-87) & $51 \mathrm{~m}(3-101)$ & $\mathrm{IHC}(14.10)$ & scores $\geq 30$ & OS \\
\hline Zeimet & 2013 & Austria & Endometrial cancer & IA-IB & 1021 & $64 \mathrm{y}(34-96)$ & $5.3 \mathrm{y}$ & $\operatorname{IHC}(14.10)$ & $>10 \%$ & DFS, OS \\
\hline Bosse & 2014 & Netherlands & Endometrial cancer & IB-IIA & 865 & $68.1 \mathrm{y}(41-90)$ & NA & $\operatorname{IHC}(14.10)$ & $>10 \%$ & OS \\
\hline Doberstein & 2014 & Germany & Breast cancer & pT1-pT4 & 52 & 58.7 y $(33-84)$ & $67.4 \mathrm{~m}$ & $\mathrm{IHC}(14.10)$ & $>10 \%$ & DFS, OS \\
\hline Ito & 2014 & Japan & Gastric cancer & I-IV & 112 & NA & NA & RT-PCR & NA & DFS, OS \\
\hline Van & 2016 & Netherlands & Endometrial cancer & I-IV & 116 & $66.3 \mathrm{y}(21-85)$ & $28.6 \mathrm{~m}(0.3-120)$ & $\operatorname{IHC}(14.10)$ & $>10 \%$ & RFS \\
\hline Smogeli & 2016 & Norway & Endometrial cancer & IA-IB & 388 & NA & $4.8 \mathrm{y}(0.1-8.8)$ & $\mathrm{IHC}(14.10)$ & $>10 \%$ & RFS, OS \\
\hline Abdel & 2016 & Austria & Ovarian cancer & I-IV & 138 & $62.8 \mathrm{y}$ & $44 \mathrm{~m}(1-242)$ & RT-PCR & $>0.23$ & PFS, OS \\
\hline Dellinger & 2016 & USA & Endometrial cancer & I-IV & 545 & 64 y $(31-90)$ & $23 \mathrm{~m}(0-192)$ & RNA-seq & $>5.37$ fold & OS \\
\hline Geels & 2016 & Netherlands & Endometrial cancer & I-IV & 103 & $63 \mathrm{y}(24-86)$ & $57 \mathrm{~m}(0-148)$ & $\mathrm{IHC}(14.10)$ & $>10 \%$ & DSS, PFS \\
\hline Notaro & 2016 & Austria & Endometrial cancer & I-IV & 82 & NA & $\begin{array}{c}11.6 \mathrm{y}(0.17- \\
21.88)\end{array}$ & RT-PCR & $>10 \%$ & DFS, OS \\
\hline Trietsch & 2016 & Netherlands & Vulvar cancer & I-IV & 348 & $71 \mathrm{y}$ & $4 \mathrm{y}$ & $\operatorname{IHC}(14.10)$ & $\geq 5 \%$ & DSS, OS \\
\hline Van & 2016 & Multiple & Endometrial cancer & I-IV & 1199 & $64 \mathrm{y}(31-93)$ & $62 \mathrm{~m}(0-229)$ & $\operatorname{IHC}(14.10)$ & $>10 \%$ & DFS, OS \\
\hline
\end{tabular}

Abbreviations: GIST, gastrointestinal stromal tumors; PDAC, pancreatic ductal adenocarcinoma; NA, not available; IHC, immunohistochemistry; OS, overall survival; DFS, disease-free survival; DSS, disease-specific survival; RFS, recurrence-free survival; PFS, progression-free survival. 
Table 2: Results of subgroup meta-analysis of different tumor types reported

\begin{tabular}{|c|c|c|c|c|c|c|c|c|c|c|c|c|}
\hline \multirow{2}{*}{ Tumor types } & \multicolumn{3}{|c|}{ OS } & \multicolumn{3}{|c|}{ DFS } & \multicolumn{3}{|c|}{ PFS/RFS } & \multicolumn{3}{|c|}{ DSS } \\
\hline & No./case & $\operatorname{HR}(95 \% \mathrm{CI})$ & $I^{2}(\%)$ & No./case & $\operatorname{HR}(95 \% \mathrm{CI})$ & $I^{2}(\%)$ & No./case & HR(95\%CI) & $I^{2}(\%)$ & No./case & $\operatorname{HR}(95 \% \mathrm{CI})$ & $I^{2}(\%)$ \\
\hline Colorectal cancer & $4 / 598$ & $\begin{array}{l}2.96(1.45- \\
6.03)\end{array}$ & 59.9 & & & & & & & $1 / 247$ & $\begin{array}{c}2.64(1.49- \\
4.66)\end{array}$ & - \\
\hline Neuroblastoma & $1 / 66$ & $\begin{array}{c}1.49(0.92- \\
2.40)\end{array}$ & - & $1 / 66$ & $\begin{array}{c}3.59(1.02- \\
12.64)\end{array}$ & - & & & & & & \\
\hline Ovarian cancer & $3 / 581$ & $\begin{array}{c}1.25(1.07- \\
1.46)\end{array}$ & 11.3 & $1 / 211$ & $\begin{array}{c}1.23(1.02- \\
1.49)\end{array}$ & - & $3 / 465$ & $\begin{array}{l}1.85(1.34- \\
2.56)\end{array}$ & 0 & & & \\
\hline $\begin{array}{l}\text { Neuroendocrine } \\
\text { tumor }\end{array}$ & $1 / 55$ & $\begin{array}{l}6.11(1.73- \\
21.66)\end{array}$ & - & $1 / 55$ & $\begin{array}{c}3.0(1.14- \\
7.89)\end{array}$ & - & & & & & & \\
\hline GIST & $3 / 340$ & $\begin{array}{l}1.85(1.31- \\
2.61)\end{array}$ & 0 & $1 / 112$ & $\begin{array}{c}0.93(0.45- \\
1.93)\end{array}$ & - & $2 / 120$ & $\begin{array}{c}4.50(1.61- \\
12.59)\end{array}$ & 0 & & & \\
\hline Breast cancer & $3 / 316$ & $\begin{array}{c}2.23(0.94- \\
5.30)\end{array}$ & 48.3 & $2 / 219$ & $\begin{array}{l}1.32(0.59- \\
2.96)\end{array}$ & 18.9 & & & & & & \\
\hline Cholangiocarcinoma & $1 / 75$ & $\begin{array}{c}2.17(1.16- \\
4.06)\end{array}$ & - & & & & $1 / 75$ & $\begin{array}{c}1.38(0.64- \\
3.0)\end{array}$ & - & & & \\
\hline PDAC & $3 / 311$ & $\begin{array}{l}0.96(0.42- \\
2.21)\end{array}$ & 85.5 & & & & & & & & & \\
\hline Gallbladder cancer & $1 / 69$ & $\begin{array}{c}1.77(0.67- \\
4.65)\end{array}$ & - & $1 / 69$ & $\begin{array}{l}3.50(1.15- \\
10.69)\end{array}$ & - & & & & & & \\
\hline Renal cell cancer & $1 / 282$ & $\begin{array}{c}1.80(1.13- \\
2.88)\end{array}$ & - & $2 / 103$ & $\begin{array}{c}1.33(0.19- \\
9.09)\end{array}$ & 56.7 & & & & & & \\
\hline NSCLC & $1 / 472$ & $\begin{array}{c}1.31(1.01- \\
1.70)\end{array}$ & - & & & & $1 / 472$ & $\begin{array}{c}1.34(1.04- \\
1.73)\end{array}$ & - & & & \\
\hline $\begin{array}{l}\text { Hepatocellular } \\
\text { cancer }\end{array}$ & $1 / 130$ & $\begin{array}{c}3.27(1.29- \\
8.30)\end{array}$ & - & $1 / 130$ & $\begin{array}{l}2.28(1.04- \\
5.0)\end{array}$ & - & & & & & & \\
\hline Endometrial cancer & $6 / 4100$ & $\begin{array}{l}3.23(1.86- \\
5.60)\end{array}$ & 86.2 & $3 / 2302$ & $\begin{array}{c}4.44(1.86- \\
10.6)\end{array}$ & 88.6 & $4 / 879$ & $\begin{array}{c}3.93(0.90- \\
17.26)\end{array}$ & 89.7 & $1 / 103$ & $\begin{array}{c}4.91(1.68- \\
14.34)\end{array}$ & - \\
\hline Vulvar cancer & $1 / 348$ & $\begin{array}{c}1.58(1.08- \\
2.32)\end{array}$ & - & & & & & & & $1 / 348$ & $\begin{array}{c}1.7(0.97- \\
2.97)\end{array}$ & - \\
\hline Total & $30 / 7743$ & $\begin{array}{l}2.06(1.65- \\
2.57)\end{array}$ & 81.8 & $13 / 3267$ & $\begin{array}{c}2.42(1.40- \\
4.19)\end{array}$ & 89.5 & $11 / 2011$ & $\begin{array}{c}2.07(1.41- \\
3.05)\end{array}$ & 73 & $3 / 698$ & $\begin{array}{c}2.45(1.48- \\
4.05)\end{array}$ & 38.6 \\
\hline
\end{tabular}

Overall HR $(95 \% \mathrm{CI})$ was shown. No./case refers to number of studies/patients included. Abbreviations: GIST, gastrointestinal Stromal Tumor; PDAC, pancreatic ductal adenocarcinoma; NSCLC, non-small cell lung cancer.

(HR=2.45, 95\%CI 1.48-4.05, $\mathrm{P}=0.196)$ but weaker for OS $(\mathrm{HR}=2.06,95 \% \mathrm{CI} 1.65-2.57, \mathrm{P}<0.001)$. As variations in cancer types can partly attributed to study heterogeneity, a subgroup analysis based on tumour type was performed. For most of the investigated cancer types, L1CAM demonstrated a significant prognostic value (Table 2).

\section{L1CAM and overall survival}

Thirty studies $[5-8,12,14,15,17-25,27,28,30$ $37,39-41,43]$ with data from 7743 patients were available to evaluate the effect of L1CAM expression on OS. The random-effects model was applied to calculate the pooled $\mathrm{HR}$ and $95 \% \mathrm{CI}$ because of the significant heterogeneity among studies $\left(\mathrm{I}^{2}=81.8 \%, \mathrm{P}<0.01\right)$. Overall, high L1CAM expression was correlated with worse $\mathrm{OS}(\mathrm{HR}=2.06$,
95\%CI 1.65-2.57, $\mathrm{P}<0.001$ ) (Figure 2A). The subgroup analysis of different cancer types showed a similar significant association between L1CAM expression and OS in colorectal cancer, ovarian cancer, neuroendocrine tumours, gastric cancer, cholangiocarcinoma, renal cell cancer, non-small cell lung cancer, hepatocellular cancer, endometrial cancer and vulvar cancer. The remaining 4 cancer types, including neuroblastoma, breast cancer, pancreatic ductal adenocarcinoma and gallbladder cancer, also showed similar trends, although without statistical significance (Table 2).

\section{L1CAM and disease-specific survival}

Only three studies $[15,38,41]$ reported the DSS. A fixed-effects model was applied to calculate 
the pooled HR and $95 \%$ CI because low heterogeneity was detected $\left(\mathrm{I}^{2}=38.6 \%, \mathrm{p}=0.196\right)$. Patients with high L1CAM expression possessed a significantly shorter DSS than did those with low L1CAM expression $(\mathrm{HR}=2.34$, 95\%CI 1.61-3.4, $\mathrm{P}<0.001$ ) (Figure 2B). Significant associations were also observed between colorectal cancer and endometrial cancer, but there was no significant association with vulvar cancer (Table 2).

\section{L1CAM and disease-free survival}

DFS was reported in thirteen studies $[6,9,12,17$, $19,22,27,31,33,36,39,43]$ covering 3267 patients. Figure $3 \mathrm{~A}$ shows the DFS outcome and demonstrates that cancer patients with high L1CAM expression have a shorter DFS than the control group (pooled $\mathrm{HR}=2.42$, $95 \%$ CI 1.40-4.19, $\mathrm{P}=0.002$ ). Subgroup analyses based

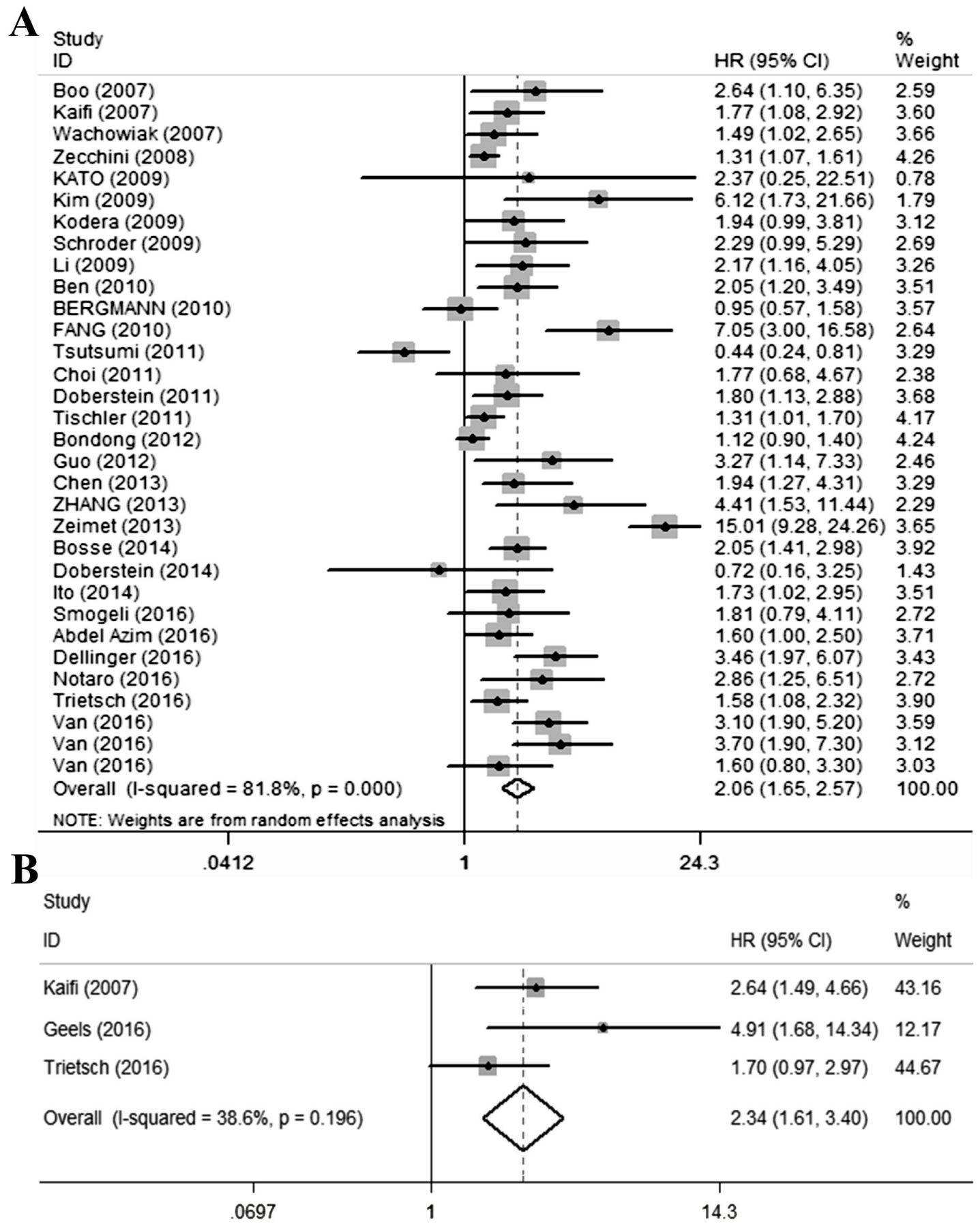

Figure 2: Qualitative meta-analysis of studies estimating the relationship between high L1CAM expression and the prognosis of patients with solid tumours. A. Overall survival B. Disease-specific survival. Abbreviations: HR, hazard ratio; CI, confidence interval. 
on cancer types revealed significant reverse associations between L1CAM expression and DFS in neuroblastoma, ovarian cancer, neuroendocrine tumours, gallbladder cancer, hepatocellular cancer and endometrial cancer (Table 2).

\section{L1CAM and progression-free survival/ recurrence-free survival}

Due to the similar endpoints in progression-free survival and recurrence-free survival, a quantitative synthesis was performed in combination. A total of 11

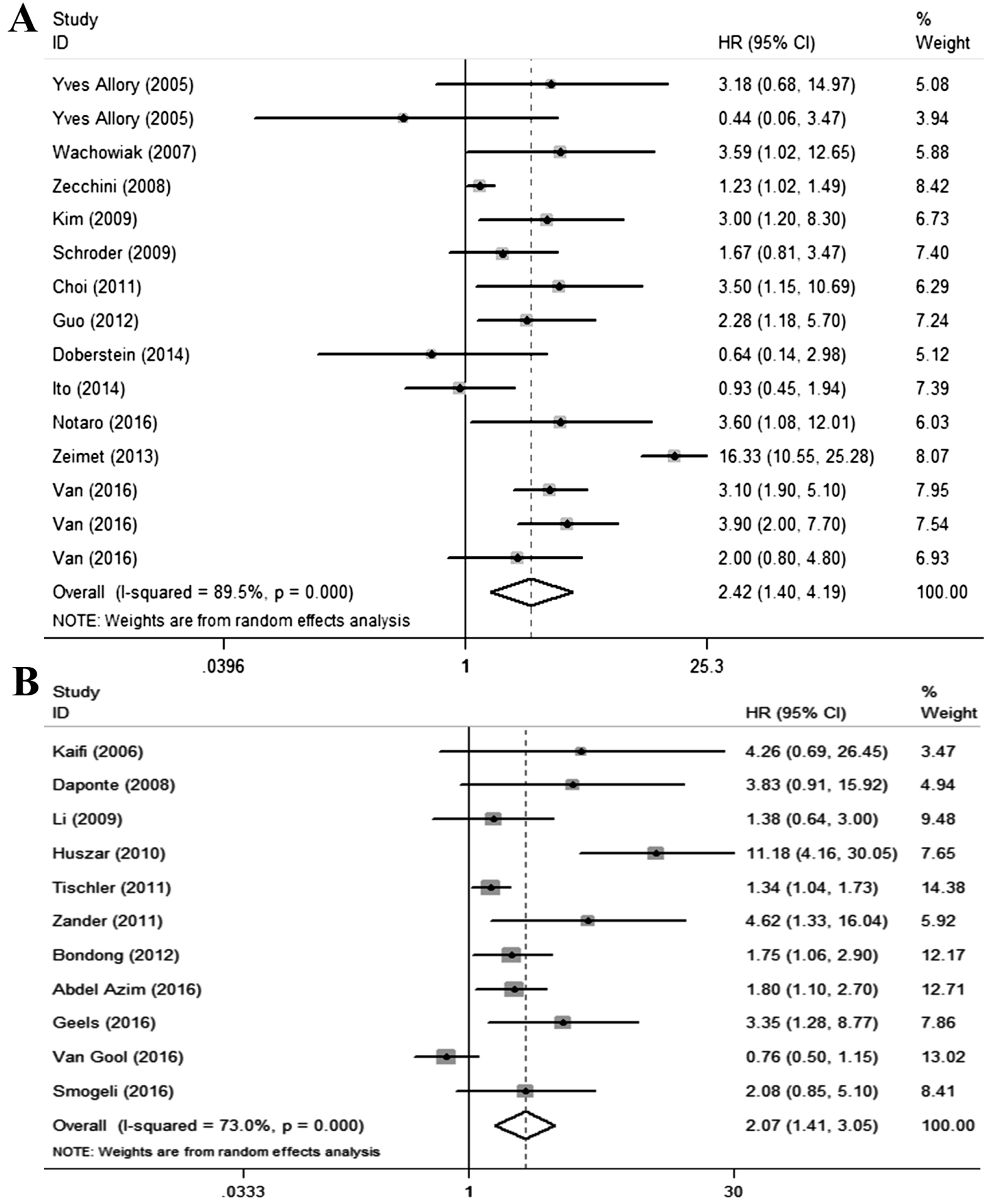

Figure 3: Qualitative meta-analysis of studies estimating the relationship between high L1CAM expression and the prognosis of patients with solid tumours. A. Disease-free survival B. PFS/RFS. Abbreviations: PFS, progression-free survival; RFS, recurrence-free survival; HR, hazard ratio; CI, confidence interval. 
studies [7, 13, 16, 21, 26, 29, 30, 37, 38, 40, 42] estimated the prognostic value of L1CAM expression on PFS/RFS. Consistent with the above results, significantly shorter PFS/RFS was observed in cancer patients expressing high levels of L1CAM (pooled HR=2.07, 95\%CI 1.41-3.05, $\mathrm{p}<0.001$ ) (Figure 3B). Subgroup analysis demonstrated similar effect of L1CAM expression on cancer types for PFS/RFS in ovarian cancer, gastric cancer, and NSCLC. However, the results were not consistent in extrahepatic cholangiocarcinoma and endometrial cancer (Table 2).

\section{Heterogeneity and sensitivity analysis}

There was significant heterogeneity $\left(\mathrm{I}^{2}>50 \%\right)$ between studies in OS, DFS and PFS/RFS analyses. A random-effect model was therefore adopted in these studies in addition to DSS. A meta-regression analysis with publication year, published country (from European or not), number of patients, and detected methods (IHC or not) as covariates was conducted. All covariates were preliminarily fit into the meta-regression model to identify covariates with highest $\mathrm{p}$ values; then, these variables were deleted one at a time to identify potential sources of heterogeneity. In terms of OS and PFS/RFS, none of these covariates were verified as a significant source of heterogeneity. Whereas the number of patients included in each individual study may be a source of heterogeneity for DFS (Coef. $=0.002, \mathrm{P}=0.038$ ) (Table $3)$. The sensitivity analysis indicated a stable result for both OS and PFS/RFS after using the leave-oneout method. However, the sensitivity analysis result was unstable for DFS after removing the study from Zeimet [33], which indicates that additional studies are needed to obtain more credible results (Supplementary Figure S1).

\section{Publication bias}

A funnel plot utilizing Egger's and Begg's rank correlation tests were conducted to evaluate the publication bias of the incorporated studies. The funnel plots for DSS and DFS (Figure 4B and 4C) were nearly symmetrical via visual inspection, and no significant publication bias was detected using Egger's test $(\mathrm{P}=0.390$ for $\mathrm{DSS}, \mathrm{P}=0.471$ for $\mathrm{DFS})$, whereas both asymmetrical funnel plots and Egger's tests for OS and PFS/RFS indicated the existence of publication bias. To validate these results, a nonparametric Trim and Fill Method was employed. No "deleted studies" was filled for OS, and the estimated HR remained stable (Figure 4A). As for PFS/RFS, five studies were filled and no obvious asymmetry was observed in the funnel plot (Figure 4D), and the HR and 95\%CI were not markedly altered. These results suggested that there were no significant publication bias between the eligible studies.

\section{DISCUSSION}

Since the first record on the analysis of L1CAM expression in human cancer published in 2003 [44], more than sixty studies have explored the role of L1CAM expression in over eighteen types of tumours or malignancies in larger patient groups. The meta-analysis presented herein is the first comprehensive description of all reported studies investigating the impact of L1CAM expression in human tumours on prognosis. Overall, the results obtained for all of the endpoints evaluated showed that L1CAM might serve as an unexceptionable biomarker to predict the unfavourable outcomes for cancer patients. These results were further confirmed in a subgroup analysis stratified based on tumour types. More specifically, the prognostic value of L1CAM for patients with ovarian cancer, endometrial cancer, neuroendocrine tumours, colorectal cancer, and hepatocellular cancer were eminently remarkable. In addition, the predictive role of L1CAM in the prognoses of neuroblastoma, gallbladder cancer, renal cell cancer, gastrointestinal stromal tumours and several additional tumours is controversial, and some studies did not consistently show significance. Notably, few studies were available for the stratified analysis of several cancer types. Moreover, studies with larger sample sizes and high-quality data are warranted to validate these results.

The biological role of L1CAM may explain its poor prognostic value. In vitro or in vivo studies combined with the overexpression or depletion of L1CAM has shed light on the involvement of L1CAM in carcinogenesis and the development of several malignancies. The functional role of L1CAM in tumour cell invasion and motility primarily depends on ectodomain cleavage from membrane proximal proteolysis, binding partner alterations and integrin binding [2, 45]. Apart from the direct prognostic implications of L1CAM in cancer patients, L1CAM expression was positively associated with tumour progression, lymph node metastasis and the risk of loco regional or distant recurrence in most included cancer types. Recent studies have suggested a close connection between L1CAM and the epithelial-mesenchymal transition (EMT). High L1CAM expression was frequently observed at the invasive front of cancers with high vimentin and absent E-cadherin expression [26]. Both EMT and Wnt signalling regulators regulate L1CAM expression [46]. In addition, evidence has indicated a role for L1CAM in facilitating metastasis formation, pro-angiogenesis and resistance to chemotherapy [3, 4, 47, 48].

The present meta-analysis identifying a correlation between high L1CAM expression and worse outcome has some limitations. Despite the rigorous inclusion criteria, significant heterogeneity was detected in a majority of the meta-analyses with different endpoints. 
Table 3: Meta-regression results of L1CAM expression on patient outcomes

\begin{tabular}{|c|c|c|c|c|c|c|c|c|c|}
\hline & \multicolumn{3}{|c|}{ OS } & \multicolumn{3}{|c|}{ PFS/RFS } & \multicolumn{3}{|c|}{ DFS } \\
\hline & Coef. & Std.Err & $P$ & Coef. & Std.Err & $P$ & Coef. & Std.Err & $P$ \\
\hline Pubication year & 0.053 & 0.057 & 0.365 & -0.056 & 0.125 & 0.665 & 0.129 & 0.096 & 0.203 \\
\hline Country & -0.505 & 0.339 & 0.147 & -0.123 & 0.842 & 0.887 & -1.260 & 0.662 & 0.079 \\
\hline NO. of patients & 0.001 & 0.001 & 0.105 & 0.000 & 0.002 & 0.896 & 0.002 & 0.001 & 0.038 \\
\hline Detect method & 0.200 & 0.383 & 0.606 & 0.297 & 0.738 & 0.696 & 0.609 & 1.087 & 0.585 \\
\hline
\end{tabular}

Coef, coefficient; Std. Err, standard error.
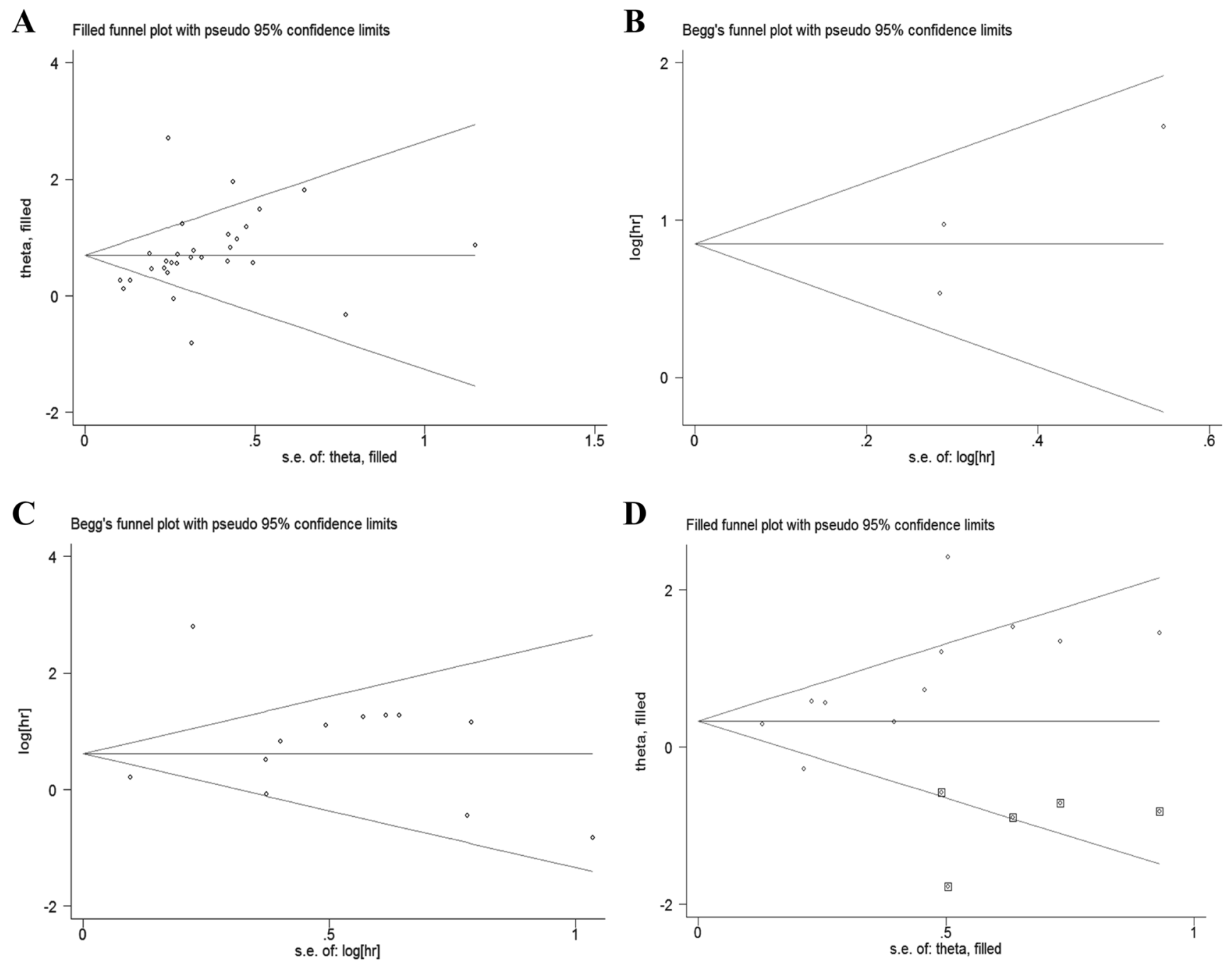

Figure 4: Begg's funnel plots for studies involved in the meta-analysis of L1CAM expression and the prognosis of patients with solid tumours. A. Overall survival (Trim and Fill method) B. Disease-specific survival C. Disease-free survival D. PFS/ RFS (Trim and Fill method, square dots display the filled studies). Abbreviations: PFS, progression-free survival; RFS, recurrence-free survival. 
Using meta-regression tests, we identified sample size as a source of heterogeneity for DFS and eliminated publication year, ethnicity, sample size and detection method as heterogeneity sources for OS and PFS/RFS. There were also several other potential reasons for the observed heterogeneity. First, difficulties in obtaining a sufficient follow-up period and homogenous endpoints limited the accuracy of these results. Second, the distinct clinical behaviour, tumour staging, pathological grade and therapeutic regimen of the various solid tumours and one defined tumour type may have influenced the clinical outcomes because cancer patients with highly aggressive and advanced stage cancers are likely to have unfavourable prognoses. Third, the arbitrary cut-off points adopted in each of the included studies might have also served as potential sources of heterogeneity. Publication bias accounts for another important factor influence on the results. A comprehensive search and screening in different databases were conducted to minimize publication bias. Apart from the 37 identified eligible studies, five studies [44, 49-52] were excluded due to incomplete reporting. Thus, there was publication bias because not all of these studies were statistically significant. The present metaanalysis showed a publication bias for OS and PFS/RFS, according to the funnel plot and Egger's test. Nevertheless, the results remained stable after applying the trim and fill method; consequently, the effect of publication bias on this association might be minimal.

In conclusion, the present comprehensive metaanalysis of 37 studies with 8552 patients suggests that high L1CAM expression might be a prognostic factor for poor outcome in patients with various cancer types. This observation requires further multicentre prospective studies using a larger cohort sample size, adjusted individual data and a unified detection method to achieve a more persuasive conclusion.

\section{MATERIALS AND METHODS}

\section{Literature searching strategies}

The question of the meta-analysis was defined as: "what is the prognostic value of L1CAM expression in patients with tumours?" Accordingly, three distinctive keywords were identified, i.e., L1CAM, prognosis and tumour. The search algorithm was applied as the three keywords combined with a free text in any of the formulations or truncations. A comprehensive search was performed in PubMed (Supplementary Table S3), EMBASE and Web of Science databases prior to October 8, 2016.

\section{Screening of records}

The first round of screening was conducted on the basis of title after duplicates removed, whereas further screening involved a detailed evaluation of the abstract and full-text. The following inclusion criteria were used: 1) papers investigating the role of L1CAM in the prognosis of human cancer; 2) a detailed protocol, including material source, methodology, quantification methods and threshold, was provided; 3) the full text was available and provided sufficient data for individual HR and 95\% CI extracting or calculating; and 4) a minimum of 1 year of follow-up time for all endpoints. Studies presented with case reports, reviews, insufficient data, and the absence of statistical analysis were excluded.

\section{Data extraction and quality assessment}

Two investigators independently extracted the data from each eligible paper. Several different parameters were collected, if provided, including the first author name, publication year, country, cancer type, cancer stage or grade, number of patients, median age of patients, median follow-up time, detection method, cutoff value, outcome definition, HR and 95\% CI for the high L1CAM expression group versus the low L1CAM expression group. HR and 95\% CI were estimated according to Tierney et al [53] when the univariate HR and $95 \% \mathrm{CI}$ were unavailable. Multivariate $\mathrm{HR}$ and $95 \%$ CI were employed when both univariate and multivariate results were provided. The Newcastle-Ottawa-Scale (NOS) was adopted to assess the study quality of each individual study. The NOS score ranged from 0 to 9 , and studies with NOS score $\geq 7$ were defined as high-quality studies.

\section{Meta-analysis methods}

Meta-analysis was performed using Stata version 12.0 (StataCorp, College Station, TX, USA). The following outcome endpoints were addressed: overall survival (OS), disease-free survival (DFS), diseasespecific survival (DSS), progression-free survival (PFS), and recurrence-free survival (RFS). Pooled HR and 95\% CI for each outcome endpoints were calculated. The fixed-effects model was adopted when no statistically significant heterogeneity was observed between studies $\left(\mathrm{P}_{\mathrm{Q}}>0.05, \mathrm{I}^{2}<50 \%\right)$, and when significant heterogeneity was observed across studies $\left(\mathrm{P}_{\mathrm{Q}}<0.05, \mathrm{I}^{2}>50 \%\right)$, the random-effects model was applied [54]. Meta-regression was conducted to identify the source when significant heterogeneity was observed. The assigned weight for each study was based on its inverse variance. The sensitivity analysis was performed using the leave-one-out method to explore the effects of each individual report on the pooled HR estimated. Further, Begg's funnel plot and Egger's test were conducted to identify publication bias [55]. Asymmetric funnel plots or $\mathrm{P}<0.05$ in Egger's test suggest the existence of publication bias. The nonparametric trim and fill method [56] was used to validate the results when significant publication bias existed. 


\section{CONFLICTS OF INTEREST}

The authors declare no conflicts of interest.

\section{REFERENCES}

1. Kamiguchi H, Hlavin ML, Lemmon V. Role of L1 in neural development: what the knockouts tell us. Molecular and cellular neurosciences. 1998; 12:48-55.

2. Kiefel H, Bondong S, Hazin J, Ridinger J, Schirmer U, Riedle S, Altevogt P. L1CAM: a major driver for tumor cell invasion and motility. Cell adhesion \& migration. 2012; 6:374-384.

3. Gavert N, Sheffer M, Raveh S, Spaderna S, Shtutman M, Brabletz T, Barany F, Paty P, Notterman D, Domany E, Ben-Ze'ev A. Expression of L1-CAM and ADAM10 in human colon cancer cells induces metastasis. Cancer research. 2007; 67:7703-7712.

4. Sebens Muerkoster S, Werbing V, Sipos B, Debus MA, Witt M, Grossmann M, Leisner D, Kotteritzsch J, Kappes H, Kloppel G, Altevogt P, Folsch UR, Schafer H. Drug-induced expression of the cellular adhesion molecule L1CAM confers anti-apoptotic protection and chemoresistance in pancreatic ductal adenocarcinoma cells. Oncogene. 2007; 26:2759-2768.

5. Dellinger TH, Smith DD, Ouyang C, Warden CD, Williams JC, Han ES. L1CAM is an independent predictor of poor survival in endometrial cancer - An analysis of The Cancer Genome Atlas (TCGA). Gynecologic oncology. 2016; 141:336-340.

6. Doberstein K, Milde-Langosch K, Bretz NP, Schirmer U, Harari A, Witzel I, Ben-Arie A, Hubalek M, Muller-Holzner E, Reinold S, Zeimet AG, Altevogt P, Fogel M. L1CAM is expressed in triple-negative breast cancers and is inversely correlated with androgen receptor. BMC cancer. 2014; 14:958.

7. Tischler V, Pfeifer M, Hausladen S, Schirmer U, Bonde AK, Kristiansen G, Sos ML, Weder W, Moch H, Altevogt $\mathrm{P}$, Soltermann A. L1CAM protein expression is associated with poor prognosis in non-small cell lung cancer. Molecular cancer. 2011; 10:127.

8. Tsutsumi S, Morohashi S, Kudo Y, Akasaka H, Ogasawara H, Ono M, Takasugi K, Ishido K, Hakamada K, Kijima H. L1 Cell adhesion molecule (L1CAM) expression at the cancer invasive front is a novel prognostic marker of pancreatic ductal adenocarcinoma. Journal of surgical oncology. 2011; 103:669-673.

9. Allory Y, Matsuoka Y, Bazille C, Christensen EI, Ronco $\mathrm{P}$, Debiec $\mathrm{H}$. The $\mathrm{L} 1$ cell adhesion molecule is induced in renal cancer cells and correlates with metastasis in clear cell carcinomas. Clinical cancer research. 2005; 11:1190-1197.

10. Alexandrescu DT, Kauffman CL, Jatkoe TA, Hartmann DP, Vener T, Wang H, Derecho C, Rajpurohit Y, Wang Y, Palma JF. Melanoma-specific marker expression in skin biopsy tissues as a tool to facilitate melanoma diagnosis. The Journal of investigative dermatology. 2010; 130:1887-1892.

11. Suzuki T, Izumoto $\mathrm{S}$, Fujimoto $\mathrm{Y}$, Maruno $\mathrm{M}$, Ito $\mathrm{Y}$, Yoshimine T. Clinicopathological study of cellular proliferation and invasion in gliomatosis cerebri: important role of neural cell adhesion molecule L1 in tumour invasion. Journal of clinical pathology. 2005; 58:166-171.

12. Wachowiak R, Fiegel HC, Kaifi JT, Quaas A, Krickhahn A, Schurr PG, Erttmann R, Schachner M, Kluth D, Sauter G, Izbicki JR. L1 is associated with favorable outcome in neuroblastomas in contrast to adult tumors. Annals of surgical oncology. 2007; 14:3575-3580.

13. Kaifi JT, Strelow A, Schurr PG, Reichelt U, Yekebas EF, Wachowiak R, Quaas A, Strate T, Schaefer H, Sauter G, Schachner M, Izbicki JR. L1 (CD171) is highly expressed in gastrointestinal stromal tumors. Modern pathology. 2006; 19:399-406.

14. Boo YJ, Park JM, Kim J, Chae YS, Min BW, Um JW, Moon HY. L1 expression as a marker for poor prognosis, tumor progression, and short survival in patients with colorectal cancer. Annals of surgical oncology. 2007; 14:1703-1711.

15. Kaifi JT, Reichelt U, Quaas A, Schurr PG, Wachowiak R, Yekebas EF, Strate T, Schneider C, Pantel K, Schachner M, Sauter G, Izbicki JR. L1 is associated with micrometastatic spread and poor outcome in colorectal cancer. Modern pathology. 2007; 20:1183-1190.

16. Daponte A, Kostopoulou E, Kollia P, Papamichali R, Vanakara P, Hadjichristodoulou C, Nakou M, Samara S, Koukoulis G, Messinis IE. L1 (CAM) (CD171) in ovarian serous neoplasms. European journal of gynaecological oncology. 2008; 29:26-30.

17. Zecchini S, Bianchi M, Colombo N, Fasani R, Goisis G, Casadio C, Viale G, Liu J, Herlyn M, Godwin AK, Nuciforo $\mathrm{PG}$, Cavallaro U. The differential role of L1 in ovarian carcinoma and normal ovarian surface epithelium. Cancer research. 2008; 68:1110-1118.

18. Kato K, Maesawa C, Itabashi T, Fujisawa K, Otsuka K, Kanno S, Tada H, Tatemichi Y, Kotani K, Oikawa H, Sugai T, Wakabayashi G, Masuda T. DNA hypomethylation at the $\mathrm{CpG}$ island is involved in aberrant expression of the $\mathrm{L} 1$ cell adhesion molecule gene in colorectal cancer. International journal of oncology. 2009; 35:467-476.

19. Kim HS, Yi SY, Jun HJ, Ahn JS, Ahn MJ, Lee J, Kim Y, Cui ZY, Hong HJ, Kim JM, Li S, Hwang IG, Park K. L1 cell adhesion molecule as a predictor for recurrence in pulmonary carcinoids and large-cell neuroendocrine tumors. APMIS. 2009; 117:140-146.

20. Kodera $Y$, Nakanishi H, Ito S, Misawa K, Ito Y, Nakayama G, Koike M, Fujiwara M, Yamamura Y, Nakao A. Expression of L1 cell adhesion molecule is a significant prognostic factor in pT3-stage gastric cancer. Anticancer research. 2009; 29:4033-4039.

21. Li S, Jo YS, Lee JH, Min JK, Lee ES, Park T, Kim JM, Hong HJ. L1 cell adhesion molecule is a novel independent 
poor prognostic factor of extrahepatic cholangiocarcinoma. Clinical cancer research. 2009; 15:7345-7351.

22. Schroder C, Schumacher U, Fogel M, Feuerhake F, Muller V, Wirtz RM, Altevogt P, Krenkel S, Janicke F, MildeLangosch K. Expression and prognostic value of L1-CAM in breast cancer. Oncology reports. 2009; 22:1109-1117.

23. Ben QW, Wang JC, Liu J, Zhu Y, Yuan F, Yao WY, Yuan YZ. Positive expression of L1-CAM is associated with perineural invasion and poor outcome in pancreatic ductal adenocarcinoma. Annals of surgical oncology. 2010; 17:2213-2221.

24. Bergmann F, Wandschneider F, Sipos B, Moldenhauer G, Schniewind B, Welsch T, Schirrmacher P, Kloppel G, Altevogt P, Schafer H, Sebens Muerkoster S. Elevated L1CAM expression in precursor lesions and primary and metastastic tissues of pancreatic ductal adenocarcinoma. Oncology reports. 2010; 24:909-915.

25. Fang QX, Lu LZ, Yang B, Zhao ZS, Wu Y, Zheng XC. L1, beta-catenin, and E-cadherin expression in patients with colorectal cancer: correlation with clinicopathologic features and its prognostic significance. Journal of surgical oncology. 2010; 102:433-442.

26. Huszar M, Pfeifer M, Schirmer U, Kiefel H, Konecny GE, Ben-Arie A, Edler L, Munch M, Muller-Holzner E, JerabekKlestil S, Abdel-Azim S, Marth C, Zeimet AG, Altevogt P, Fogel M. Up-regulation of L1CAM is linked to loss of hormone receptors and E-cadherin in aggressive subtypes of endometrial carcinomas. The Journal of pathology. 2010; 220:551-561.

27. Choi SY, Jo YS, Huang SM, Liang ZL, Min JK, Hong HJ, Kim JM. L1 cell adhesion molecule as a novel independent poor prognostic factor in gallbladder carcinoma. Human pathology. 2011; 42:1476-1483.

28. Doberstein K, Wieland A, Lee SB, Blaheta RA, Wedel S, Moch H, Schraml P, Pfeilschifter J, Kristiansen G, Gutwein P. L1-CAM expression in ccRCC correlates with shorter patients survival times and confers chemoresistance in renal cell carcinoma cells. Carcinogenesis. 2011; 32:262-270.

29. Zander H, Rawnaq T, von Wedemeyer M, Tachezy M, Kunkel M, Wolters G, Bockhorn M, Schachner M, Izbicki JR, Kaifi J. Circulating levels of cell adhesion molecule L1 as a prognostic marker in gastrointestinal stromal tumor patients. BMC cancer. 2011; 11:189:181-187.

30. Bondong S, Kiefel H, Hielscher T, Zeimet AG, Zeillinger R, Pils D, Schuster E, Castillo-Tong DC, Cadron I, Vergote I, Braicu I, Sehouli J, Mahner S, Fogel M, Altevogt P. Prognostic significance of L1CAM in ovarian cancer and its role in constitutive NF-kappaB activation. Annals of oncology. 2012; 23:1795-1802.

31. Guo X, Xiong L, Zou L, Sun T, Zhang J, Li H, Peng R, Zhao J. L1 cell adhesion molecule overexpression in hepatocellular carcinoma associates with advanced tumor progression and poor patient survival. Diagnostic pathology. 2012; 7:96.
32. Chen DL, Zeng ZL, Yang J, Ren C, Wang DS, Wu WJ, Xu $\mathrm{RH}$. L1cam promotes tumor progression and metastasis and is an independent unfavorable prognostic factor in gastric cancer. Journal of hematology \& oncology. 2013; 6:43.

33. Zeimet AG, Reimer D, Huszar M, Winterhoff B, Puistola U, Azim SA, Muller-Holzner E, Ben-Arie A, van Kempen LC, Petru E, Jahn S, Geels YP, Massuger LF, Amant F, Polterauer S, Lappi-Blanco E, et al. L1CAM in early-stage type I endometrial cancer: results of a large multicenter evaluation. Journal of the National Cancer Institute. 2013; 105:1142-1150.

34. Zhang C, Fan Y, Li W, Li Y, Li S, Qian X, Lin Y, Liu F, Lang $\mathrm{R}, \mathrm{Gu} \mathrm{F}, \mathrm{Fu}$ L. Expression and significance of Ll-CAM in invasive micropapillary carcinoma of the breast. Chinese Journal of Clinical Oncology. 2013; 40:198-201.

35. Bosse T, Nout RA, Stelloo E, Dreef E, Nijman HW, Jurgenliemk-Schulz IM, Jobsen JJ, Creutzberg CL, Smit VT. L1 cell adhesion molecule is a strong predictor for distant recurrence and overall survival in early stage endometrial cancer: pooled PORTEC trial results. European journal of cancer (Oxford, England: 1990). 2014; 50:2602-2610.

36. Ito T, Yamada S, Tanaka C, Ito S, Murai T, Kobayashi D, Fujii T, Nakayama G, Sugimoto H, Koike M, Nomoto S, Fujiwara M, Kodera Y. Overexpression of L1CAM is associated with tumor progression and prognosis via ERK signaling in gastric cancer. Annals of surgical oncology. 2014; $21: 560-568$.

37. Abdel Azim S, Duggan-Peer M, Sprung S, Reimer D, Fiegl $\mathrm{H}$, Soleiman A, Marth C, Zeimet AG. Clinical impact of L1CAM expression measured on the transcriptome level in ovarian cancer. Oncotarget. 2016; 7:37205-37214. doi: 10.18632/oncotarget.9291.

38. Geels YP, Pijnenborg JM, Gordon BB, Fogel M, Altevogt P, Masadah R, Bulten J, van Kempen LC, Massuger LF. L1CAM Expression is Related to Non-Endometrioid Histology, and Prognostic for Poor Outcome in Endometrioid Endometrial Carcinoma. Pathology oncology research. 2016.

39. Notaro S, Reimer D, Duggan-Peer M, Fiegl H, Wiedermair A, Rossler J, Altevogt P, Marth C, Zeimet AG. Evaluating L1CAM expression in human endometrial cancer using qRT-PCR. Oncotarget. 2016; 7:40221-40232. doi: 10.18632/oncotarget.9574.

40. Smogeli E, Davidson B, Cvancarova M, Holth A, Katz B, Risberg B, Kristensen G, Lindemann K. L1CAM as a prognostic marker in stage I endometrial cancer: a validation study. BMC cancer. 2016; 16:596.

41. Trietsch MD, Oonk MH, Hawinkels LJ, Bor R, van Eendenburg JD, Ivanova Z, Peters AA, Nijman HW, Gaarenstroom KN, Bosse T. Prognostic value and clinicopathologic characteristics of L1 cell adhesion molecule (L1CAM) in a large series of vulvar squamous cell carcinomas. Oncotarget. 2016; 7:26192-26205. doi: 10.18632/oncotarget.8353. 
42. Van Gool IC, Stelloo E, Nout RA, Nijman HW, Edmondson RJ, Church DN, MacKay HJ, Leary A, Powell ME, Mileshkin L, Creutzberg CL, Smit VT, Bosse T. Prognostic significance of L1CAM expression and its association with mutant p53 expression in high-risk endometrial cancer. Modern pathology. 2016; 29:174-181.

43. van der Putten LJ, Visser NC, van de Vijver K, Santacana M, Bronsert P, Bulten J, Hirschfeld M, Colas E, Gil-Moreno A, Garcia A, Mancebo G, Alameda F, Trovik J, Kopperud RK, Huvila J, Schrauwen S, et al. L1CAM expression in endometrial carcinomas: an ENITEC collaboration study. British journal of cancer. 2016; 115:716-724.

44. Fogel M, Gutwein P, Mechtersheimer S, Riedle S, Stoeck A, Smirnov A, Edler L, Ben-Arie A, Huszar M, Altevogt P. L1 expression as a predictor of progression and survival in patients with uterine and ovarian carcinomas. Lancet (London, England). 2003; 362:869-875.

45. Wai Wong C, Dye DE, Coombe DR. The role of immunoglobulin superfamily cell adhesion molecules in cancer metastasis. International journal of cell biology. 2012; 2012:340296.

46. Pfeifer M, Schirmer U, Geismann C, Schafer H, Sebens S, Altevogt P. L1CAM expression in endometrial carcinomas is regulated by usage of two different promoter regions. BMC molecular biology. 2010; 11:64.

47. Stoeck A, Gast D, Sanderson MP, Issa Y, Gutwein P, Altevogt P. L1-CAM in a membrane-bound or soluble form augments protection from apoptosis in ovarian carcinoma cells. Gynecologic oncology. 2007; 104:461-469.

48. Friedli A, Fischer E, Novak-Hofer I, Cohrs S, BallmerHofer K, Schubiger PA, Schibli R, Grunberg J. The soluble form of the cancer-associated L1 cell adhesion molecule is a pro-angiogenic factor. The international journal of biochemistry \& cell biology. 2009; 41:1572-1580.

49. Wang YY, Li L, Zhao ZS, Wang YX, Ye ZY, Tao HQ. L1 and epithelial cell adhesion molecules associated with gastric cancer progression and prognosis in examination of specimens from 601 patients. Journal of experimental \& clinical cancer research. 2013; 32:66.

50. Hai J, Zhu CQ, Bandarchi B, Wang YH, Navab R, Shepherd FA, Jurisica I, Tsao MS. L1 cell adhesion molecule promotes tumorigenicity and metastatic potential in nonsmall cell lung cancer. Clinical cancer research. 2012; 18:1914-1924.

51. Du Y, Zhang H, Jiang Z, Huang G, Lu W, Wang H. Expression of L1 protein correlates with cluster of differentiation 24 and integrin betal expression in gastrointestinal stromal tumors. Oncol Lett. 2015; 9:2595-2602.

52. Dahl A, Teegen J, Altevogt P, Loning T, Schumacher U. Glycoconjugate expression in adenoid cystic carcinoma of the salivary glands: up-regulation of L1 predicts fatal prognosis. Histopathology. 2011; 59:299-307.

53. Tierney JF, Stewart LA, Ghersi D, Burdett S, Sydes MR. Practical methods for incorporating summary time-to-event data into meta-analysis. Trials. 2007; 8:16.

54. DerSimonian R, Laird N. Meta-analysis in clinical trials. Controlled clinical trials. 1986; 7:177-188.

55. Egger M, Davey Smith G, Schneider M, Minder C. Bias in meta-analysis detected by a simple, graphical test. Bmj. 1997; 315:629-634.

56. Duval S, Tweedie R. Trim and fill: A simple funnel-plotbased method of testing and adjusting for publication bias in meta-analysis. Biometrics. 2000; 56:455-463. 